\title{
Effective Input and Output in Chinese College Students' Listening and Speaking Class
}

\author{
Jimei Li \\ Xi'an Innovation College of Yan'an University, Xi'an, Shaanxi, 710100, China \\ 11850809@qq.com
}

\begin{abstract}
Listening and speaking are first two basic skills in learning a language. However, most of Chinese college students suffer from low proficiency of listening and speaking rather than those of reading and writing. Based on input and output theories as well as teaching experiences, this paper aims to explore the reasons and how to make comparatively more effective input and output and how to shorten the distance between such input and output, anticipating it would be beneficial for both second language teachers and learners.
\end{abstract}

Keywords: Listening; Speaking; Input; Output; Effectiveness.

\section{Introduction}

English is used as an international language. Knowing the language can enhance international communication in various ways from daily conversations to international trade and cooperation, etc. Its importance is quite obvious that even kindergarten kids start to learn it around 4 years old in China. Nowadays, Chinese Education Ministry has taken positive reform policies that high school students can have two opportunities to take English exam for college entrance examination and the higher points will be considered as the final score for English. Such reform, as a matter of fact, raises the standard for passing the exam, since it demands more of the students' proficiency in listening and speaking, which are commonly believed to be Chinese students' weakness in learning a second language, and even later in college period, they still feel they have great difficulty in listening and speaking.

The first reason for such a phenomenon may be because that even listening and speaking are ranked before reading, writing and translation among five basic skills, but our teachings most of the time still focuses more on the rest two or three for different purposes, for example, passing the paper tests, mainly. For a long time, our assessment system has not been in accordance with what we really expect the language teaching should be. It is hopeful that our reform may divert the attention from score-orientation to practical skills-orientation where listening and speaking skills could be given due attention, since they play significant roles in smooth communication in culture, in science, in economy, etc. This paper will focus on the ways how to improve listening and speaking by effective input and output in Chinese college students' listening and speaking class.

\section{Effective listening input as the foundation}

As for classroom teaching, researchers have different views towards Kristen's input hypothesis, which differs from previous structural pattern teaching method. It emphasizes comprehensible input, formulated as " $i+1$ ". Kristen put forward that learners advance their language learning gradually by receiving "comprehensible input". He defined comprehensible input as " $i+1$ ": $i$ represents learners' current state of knowledge, the next stage is a $\mathrm{i}+1$. By providing comprehensible input which is bit higher than the learners' current level, the learners' LAD (language acquisition device) will be activated and contribute to acquisition. In Kristen's view the input hypothesis is central to all acquisition and has implications for the classroom. Kristen's input hypothesis received criticism later for he mistook "input" as "intake" (the actual share of input that has been internalized by the learner). Although Kristen gave some indications, his input hypothesis can hardly answer the question when and what learners need in learning a second language. However, it cannot be denied that language 
input is the foundation for "intake" in acquiring almost any language, especially, learning a second language. It is always one step ahead of "intake". Such input mainly comes from listening or reading. Here we only focuses on the listening alone.

The question is how to make our listening an effective and meaningful input in teaching practice. Firstly, quality of listening materials. According to the actual level of college students' English proficiency, teachers should make their own creative choice among varieties of teaching materials and even the content to serve the students better. The listening materials should be native or at least native-like. Secondly, quantity of listening materials. As a large amount of input is needed, students should be prepared to have open ears just as a baby starts to be exposed to lots of Mummy talk before they can actually imitate and speak on their own. Thirdly, language environment is another significant factor. It is proved by some language centers that total immersion method of teaching appears more successful. Immersed in the language, students are forced to think and express themselves habitually in that target language. Such habit formation will facilitate language learning. Fourthly, context-based task as motivation. Some students would fall asleep during listening, because they take the listening materials as a lullaby. To explore further, we can notice that these groups of students lack interest or motivation for listening activity. Besides, the listening materials may also be over their head, which can be another possible reason that triggers such behavior during class time. Therefore, task-and-actual-context-based activities should be well-organized to arouse the interest as well as make it effective and meaningful listening. That is to say, listening for a purpose, to put it simple.

\section{Effective spoken output as the motivation}

Speaking is such a purposeful motivation and attainable goal in a listening and speaking class. Without related spoken output task, the listening input may not be evaluated. Without listening input, the speaking may not be prompted. The output is as equally important as the input. An effective output practice requires the teachers to be organizers and facilitators and require students to be active speakers who can apply the materials absorbed from previous listening process into a similar context verbal communication.

Effective spoken output means shortening the distance between internalizing listening materials and convert them into students' verbal expressions in order to improve their language performances. Wen qiufang (2015) introduces "The production-oriented approach to teaching university students English in China". She holds that there are two types of output, "immediate production and later-on production". Both these two types are greatly encouraged. During class time more immediate production or output is expected. However, it is undeniable that a class would fall into silence. According to Kristen's input hypothesis, such "silence period" is unavoidable before a later-on production. It means that only after large quantity of input can be accumulated to the some extent that learners can be activated to output. Such silence is an accumulative stage of learning a foreign language. It should be respected. Teachers should be fully prepared for this kind of silence period.

Besides, according to Swain's output hypothesis, we can infer that effective output could be obtained because output can arouse learner's attention on language-specific questions and evoke learners to further explore solutions to the questions based on acquired linguistic knowledge and help consolidate them. With continuous language input, learners can also revise their output. Secondly, output is like a hypothesis testing process for the previous input. It is a way to internalize previous input and test it in actual use. It can be regarded as a means of assessment for previous listening input as for language teachers as well. Thirdly, it shows that learners can synthesize and analyze problems related to the language itself over lexical or syntactic levels, etc. Therefore, effective output can serve as a strong motivation for the students. 


\section{Summary}

Effective listening and speaking are significant in meaningful learning. On the ground of input and output hypotheses, this paper simply introduces some methods to shorten the distance between listening input and spoken output.

However, language acquisition is such a complex process. There are individual differences, such as individual language aptitude, age differences, etc. Students would also employ different strategies. Among all of strategies, metacognitive strategies are scarcely used, which emphasize planning, monitoring and evaluating one's learning. Based on daily observations, students lack motivations and interest in learning English, let alone planning and evaluating their own learning process. Hence, effective input and output also partially depends on the learners. How learners are motivated, and how they use their strategies in acquiring a second language are equally significant. As for language teachers, we should motivate the students rather than discourage them and endeavor to make listening and speaking class a meaningful learning process.

\section{Acknowledgments}

Research project: English Listening Excellent Course funded by Xi'an Innovation College of Yan'an University. Project No. 14JP03.

\section{References}

[1] Ellis, R. The study of Second Language Acquisition. Oxford: Oxford University Press. 1994.

[2] Ellis, R. Understanding Second Language Acquisition. Shanghai: Shanghai Foreign Language Education Press. 1999.

[3] Larsen-Freeman, D. \& Long, M. An Introduction to Second Language Acquisition Research. Beijing: Foreign Language Teaching and Research Press. 2000.

[4] Qiufang, Wen. The production-oriented approach to teaching university students English in China. Foreign Language Teaching and Research. 2015 July, Vol. 47 No.4.

[5] Qiufang, Wen. The production-oriented approach to teaching university students English in China. Language Teaching. 2016. 